\title{
DIVERSIDAD, DISTRIBUCIÓN Y ESTRATEGIAS PARA la conservación de las Pleurothallidinae (Orchidaceae) en OAXaca
}

\author{
Rodolfo Solano-Gómez', Nancy Alonso-Hernández, Karina Rosado-Ferrer, \\ Mariana de Alba Aguilar-Hernández y Rufina García \\ Centro Interdisciplinario de Investigación para el Desarrollo Integral Regional Unidad Oaxaca, IPN, \\ Hornos 1003, Santa Cruz Xoxocotlán, C.P. 71230, Oaxaca, México \\ 'Autor para la correspondencia. Correo-e: solanogo@yahoo.com.mx
}

\begin{abstract}
Resumen: El presente trabajo se realizó para determinar las áreas con mayor diversidad de las orquídeas de la subtribu Pleurothallidinae en Oaxaca, asimismo para conocer su distribución, preferencias de habitat y regiones que son importantes para su conservación. Se revisó material colectado en el estado para el grupo; los sitios de colecta fueron georreferenciados y digitalizados sobre temas cartográficos del estado. A partir de 399 localidades se reportan 13 géneros, 120 especies y 2 subespecies para la subtribu en Oaxaca, 32 de ellas son endémicas y 12 se consideran en riesgo. El bosque mesófilo de montaña es el hábitat que alberga el mayor número de especies de Pleurothallidinae. Anathallis oblanceolata y Lepanthes nigriscapa, dos especies endémicas a Oaxaca, están problamente extintas. La Sierra Norte y Los Chimalapas albergan más localidades para Pleurothallidinae en comparación con otras regiones, por lo que se proponen como áreas prioritarias de conservación de este grupo de orquídeas.

Palabras clave: bosque mesófilo de montaña, endemismo, orquídeas, riqueza florística, SIG.

Abstract: The objectives of this paper were to locate the geographic areas with the highest diversity of Pleurothallidinae in Oaxaca, as well as their habitat preferences in order to call attention to preserve these zones. A database was constructed based on herbarium collections and literature. Localities were georeferenced and mapped. From 399 localities where species of this group were present a total of 120 species, and 2 subspecies that belong 13 genera were recorded for Oaxaca; 32 of them are endemic, and 12 are at risk. The cloud forest is the habitat with the highest number of Pleurothallidinae species. Anathallis oblanceolata and Lepanthes nigriscapa, two endemic species to Oaxaca, are probably extinct. Sierra Norte and Los Chimalapas harbor more localities for Pleurothallidinae in comparison with other areas, so that they are proposed as conservation priority areas for this orchid group.
\end{abstract}

Key words: cloud forest, endemism, GIS, floristic richness, orchids.

L a diversidad de la flora de Oaxaca se estima en más de 8,000 especies de plantas vasculares y es la más alta en México (García-Mendoza, 2004). A pesar de que en los últimos dos siglos esta riqueza llamó la atención de botánicos nacionales y extranjeros, fue apenas en las últimas tres décadas que se incrementaron notablemente las colecciones botánicas en el estado y se inició el inventario florístico de Oaxaca (García-Mendoza y Torres, 1999; García-Mendoza, 2004). La gran extensión del estado, su accidentada topografía y el difícil acceso a muchas zonas son factores que han influido en que apenas el 20\% de su territorio esté razonablemente explorado (García-Mendoza, 2004). A pe- sar de que la mayoría de los grupos de plantas no son suficientemente conocidos en el estado, una excepción son las orquídeas, una de las familias más diversas en Oaxaca, bien representada en las colecciones nacionales (Dressler y Pollard, 1974; Hágsater y Salazar, 1990; Solano, 1993, 2000; Salazar y Soto, 1996; Halbinger y Soto, 1997; Hágsater y Soto, 2003; Soto y Salazar, 2004; Salazar et al., 2006). La riqueza de Orchidaceae en Oaxaca se ha estimado en aproximadamente 700 especies pertenecientes a 144 géneros (Soto y Salazar, 2004).

Entre las orquídeas distribuídas en Oaxaca, uno de los grupos más diversos es la subtribu Pleurothallidinae, con 
123 especies, un poco más de la mitad de los reportados para México (Soto y Salazar, 2004). La riqueza de esta subtribu es similar a familias como Acanthaceae, Asclepiadaceae, Cactaceae, Convolvulaceae, Melastomataceae, Malvaceae, Piperaceae y Scrophulariaceae, que son de las más diversas en la flora oaxaqueña (García-Mendoza, 2004). Las Pleurothallidinae presentan una mayor abundancia en los bosques húmedos de las zonas tropicales de montaña, donde la gran mayoría crecen como epífitas. El grupo carece de la relevancia ornamental de muchas otras orquídeas pero su importancia es biológica, ya que suelen mostrar una alta especificidad por su hábitat y hospederos y la densidad de sus poblaciones disminuye en los bosques perturbados. Por otro lado, muchos taxones presentan una distribución muy restringida y con frecuencia se conocen de una o de escasas localidades, por lo que los endemismos son más comunes en esta subtribu que en otros grupos de orquídeas.

En el presente trabajo con base en la información de colecciones científicas, complementada con referencias bibliográficas de las Pleurothallidinae de Oaxaca, se da respuesta a las siguientes preguntas: ¿Cuál es la diversidad taxonómica de este grupo en el estado? ¿Cuál es el estado actual de exploración botánica para el grupo en Oaxaca? ¿Cuales zonas del estado requieren aún de estudios florísticos para este grupo de orquídeas? ¿Cuales hábitats son los más favorables para las Pleurothallidinae en Oaxaca y donde se localizan? y ¿Cuáles son las áreas del estado que pueden garantizar la conservación de este grupo de orquídeas? Por otro lado, el estudio es una aproximación para evaluar el estado actual de conocimiento y exploración botánica en Oaxaca con el uso de sistemas de información geográfica.

\section{Materiales y métodos}

Base de datos. Se elaboró una base de datos para incluir las localidades de las orquídeas de la subtribu Pleurothallidinae que Soto y Salazar (2004) reportaron para Oaxaca. La información de localidades se obtuvo a partir de la revisión de las colecciones de los herbarios AMO, CHAPA, ENCB, IEB, MEXU, OAX, UAMIZ y XAL; en algunos casos se tuvo acceso a especímenes depositados en las colecciones de herbarios extranjeros como AMES, MO, K, P y W. También se obtuvo información a través de una revisión bibliográfica, especialmente de la consulta de las monografías de los géneros Lepanthes (Salazar y Soto, 1996), Stelis (Solano, 1993, 2000) y Trichosalpinx (Soto, 1987), así como de los listados florísticos elaborados por Ortiz (1970), GarcíaMendoza (1983), Ishiki (1988), Saynes (1989), Torres-Colín (1989), Salas (1990), Campos y Villaseñor (1995), RuizJiménez (1995), Salazar y Hágsater (1997), Pérez-García et al. (2001), Juárez y Velasco (2003), Salas et al. (2003, 2007), Figueroa y Guzmán (2005), Martínez (2005), Salazar et al. (2006), Rosado y Aguilar (2007) y Solano et al. (2007). Para los nombres de géneros y especies de Pleurothallidinae se siguieron los criterios propuestos por Soto et al., (2007b). En el caso de las colecciones no georeferenciadas, las coordenadas geográficas fueron asignadas mediante la consulta de cartas topográficas de Oaxaca escala 1:250,000 (INEGI, 2000) y con el manual de información estadística para el estado (Anónimo, 2005). La base de datos incluyó el nombre científico, municipio, distrito, sitio de colecta, latitud, longitud y altitud.

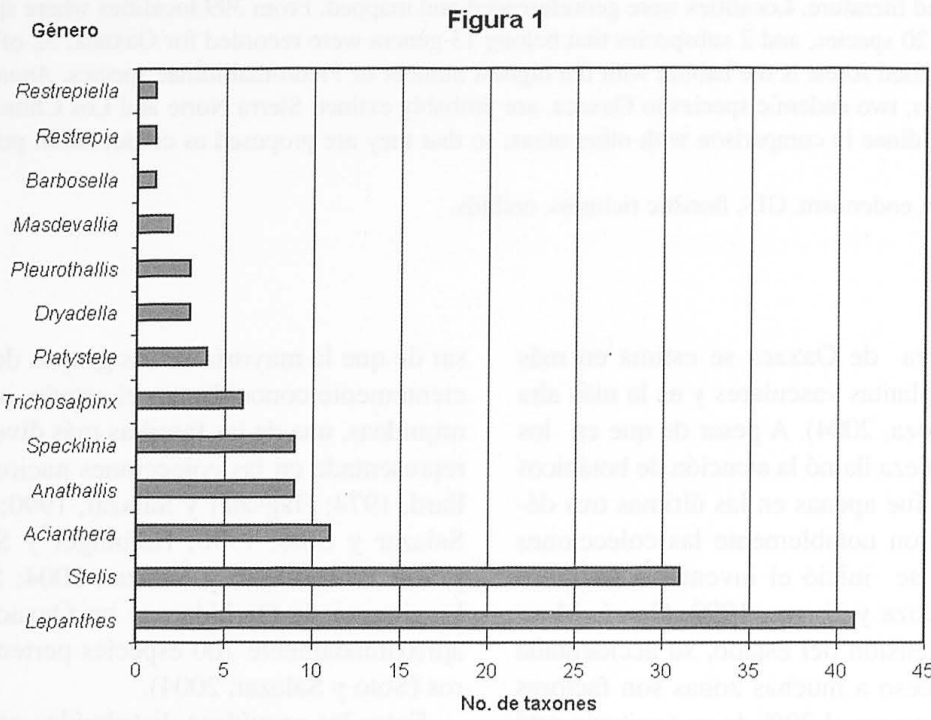

Figura 1. Riqueza específica de los trece géneros de la subtribu Pleurothallidinae presentes en Oaxaca. 


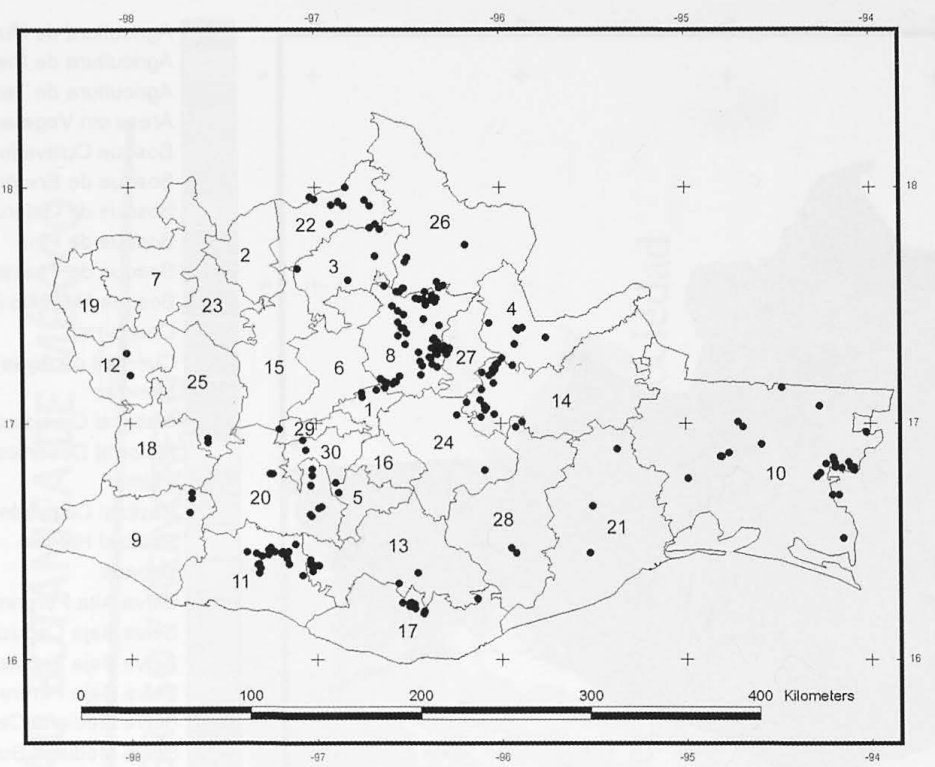

1. Centro

2. Coixtlahuaca

4. Cuicatlan

5. Ejutla

5. Ejutla

7. Huajuapa

8. Ixtlan

9. Jamiltepec

10. Juchitan

11. Juquila

12. Juxtlahuaca

13. Miahuatlan

14. Mixe

15. Nochixtlan

16. Ocotlan

17. Pochutla

18. Putla

19. Silacayoapan

20. Sola de Vega

21. Tehuantepec

22. Teotitlan

23. Teposcolula

24. Tlacolula

25. Tlaxiaco

26. Tuxtepec

27. Villa Alta

28. Yautepec

29. Zaachila

30. Zimatlan

Figura 2. Mapa de los distritos políticos de Oaxaca (CONABIO, 1998) y los sitios de colecta registrados para la subtribu Pleurothallidinae.

Sistema de Información Geográfica. Los datos de coordenadas geográficas fueron convertidos en valores decimales al formato dBase IV y exportadas al programa ArcView GIS 3.2 (Anónimo, 2000). A partir del mapa de la República Mexicana con división estatal (INEGI, 2000) se obtuvo el contorno para el estado de Oaxaca, el cual fue utilizado como mapa base para sobreponer las localidades de Pleurothallidinae. Para evaluar la distribución de las localidades en la geografía del estado se emplearon las temáticas de municipios, distritos políticos y regiones etnográfico-folkló-

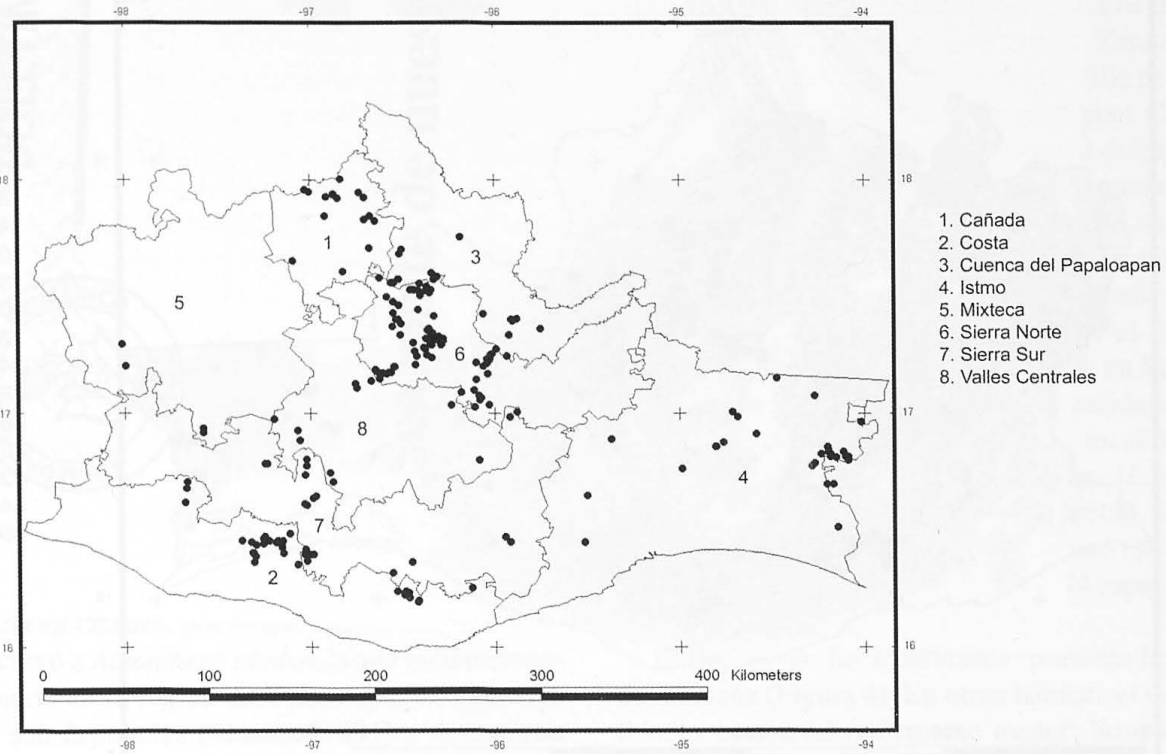

Figura 3. Mapa de las regiones etnográfico-folklóricas de Oaxaca (CONABIO, 1998) y los sitios de colecta registrados para la subtribu Pleurothallidinae. 


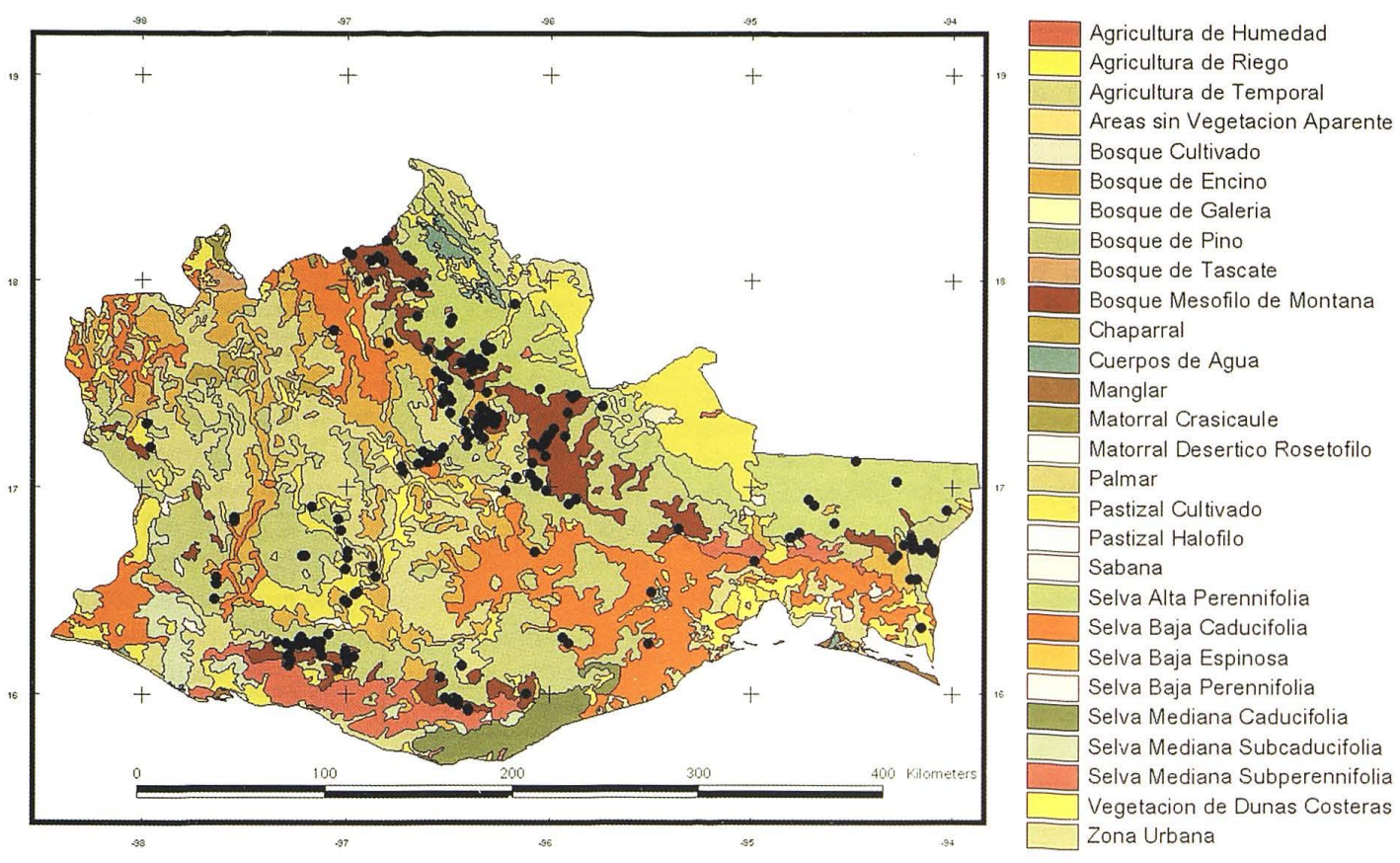

Figura 4. Mapa de uso de suelo y tipos de vegetación de Oaxaca (INEGI, 2000) y los sitios de colecta registrados para la subtribu Pleurothallidinae.

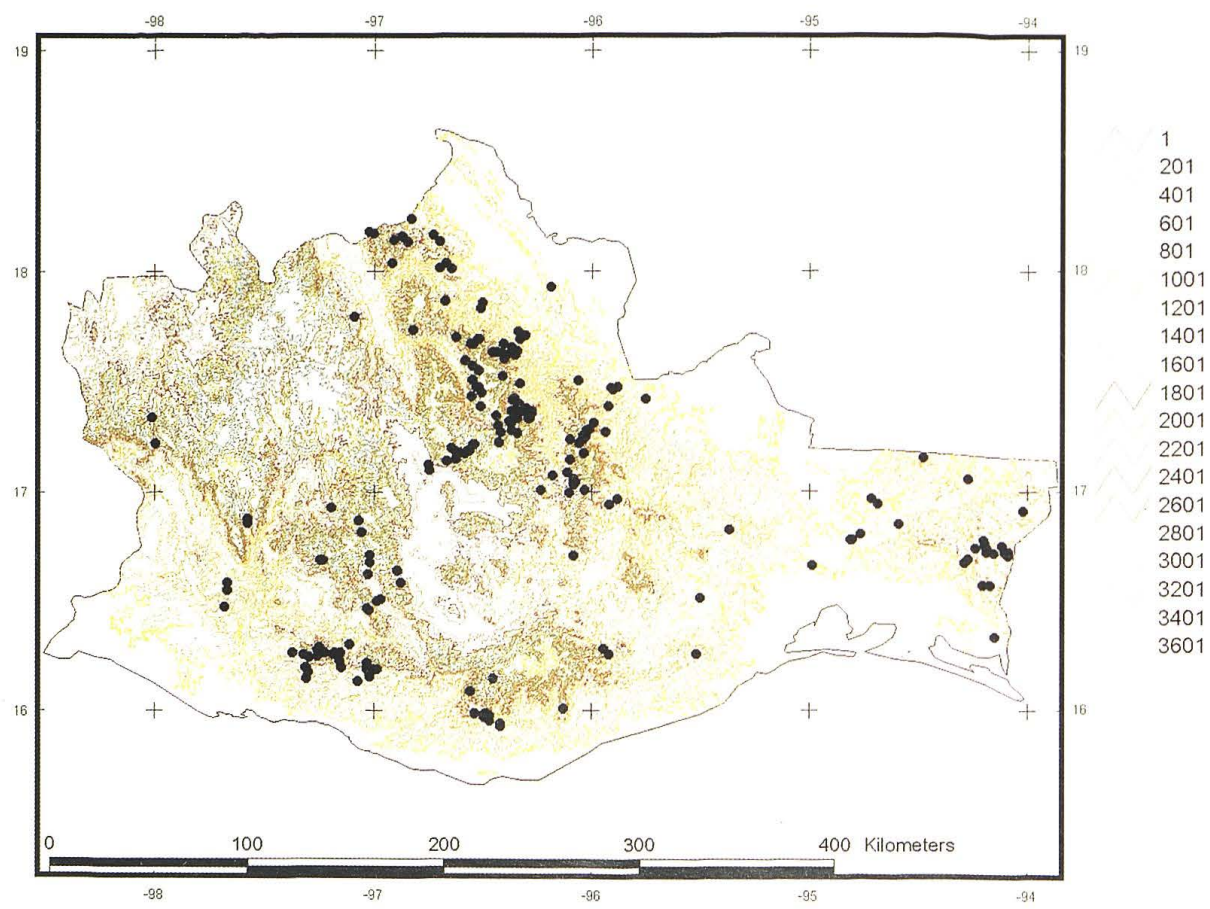

Figura 5. Mapa de curvas de nivel (CONABIO, 2000) para Oaxaca y los sitios de colecta para la subtribu Pleurothallidinae. 


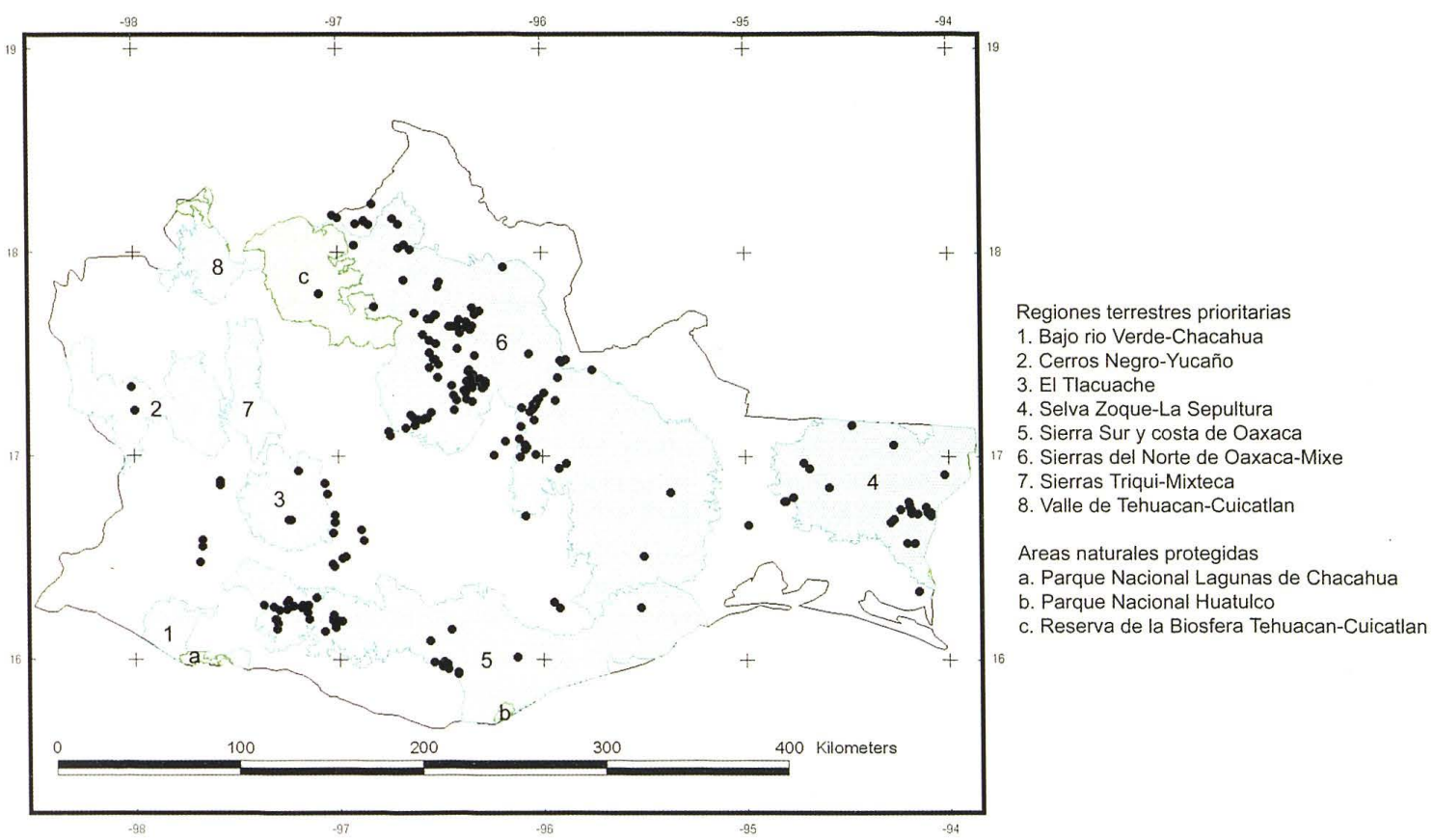

Figura 6. Mapa de las regiones terrestres prioritarias para la conservación (en azul) (CONABIO, 1998) y áreas naturales protegidas (en verde) (CONANP, 2007)

ricas de Oaxaca (CONABIO, 1998). Asimismo, para tener un panorama global sobre la distribución y conservación de la subtribu en el estado, se utilizaron las temáticas de uso de suelo y vegetación (INEGI, 2000), curvas de nivel (CONABIO, 1998), regiones terrestres prioritarias para la conservación (CONABIO, 1998) y áreas naturales protegidas (CONANP, 2007). En las últimas dos temáticas también se evaluó la distribución de los taxones endémicos y los que se encuentran en riesgo de acuerdo a la NOM-059-ECOL2001 (Semarnat, 2002). Se elaboró un mapa digitalizado para las localidades de Pleurothallidinae sobre cada temática empleada.

\section{Resultados}

Diversidad taxonómica. En el Apéndice se listan 13 géneros con 120 especies y dos subespecies de Pleurothallidinae presentes en Oaxaca. Dracula pusilla y Myoxanthus octomerioides habían sido reportadas para el estado por Soto y Salazar (2004), pero no se encontró material que confirme su presencia en Oaxaca, por lo que fueron excluidas. En cambio, se incluyó a Acianthera tikalensis que recientemente fue descubierta en la región de Chimalapa. Los géneros más diversos son Lepanthes (41), Stelis (31) y Acianthera (11) (Figura 1); 32 especies son endémicas a Oaxaca, lo que representa el $26.2 \%$ de la subtribu, de ellas 19 pertenecen a Lepanthes y 6 a Stelis. Por otro lado, 12 especies se incluyen en alguna categoría de riesgo, 3 como amenazadas y 9 sujetas a protección especial (SEMARNAT, 2002).

Estado actual de exploración botánica. Los municipios con más sitios de colecta son Tantetze de Zaragoza (38), San Juan Juquila Vijanos (36), Totontepec Villa de Morelos (32), Santa María Chimalapa (30), San Miguel Chimalapa (29) y Santiago Comaltepec (28). De los 30 distritos de Oaxaca sólo en 20 se han registrado localidades para el grupo (Figura 2), pero cinco de ellos concentran 288 sitios de colecta (el 72.2\%): Ixtlán (80), Villa Alta (74), Juchitán (59), Mixe (45) y Juquila (30). Las regiones del estado con más localidades son Sierra Norte con 199 (casi el 50 \%), seguida por el Istmo con 63 y la Costa con 48; en Valles Centrales y Mixteca solo se conocen 19 y 4 localidades, respectivamente (Figura 3). Un $25 \%$ de las localidades incluyen únicamente ocho especies de Lepanthes [L. attenuata (11), L. erythroxantha (10), L. galeottiana (12), L. moorei (11), y L. rekoi (14)] y Stelis [S. pachyglossa (16), S. oaxacana (14), S. platystylis (12)]; en cambio, 44 especies se conocen de una sola localidad.

El $66.7 \%$ de las localidades presenta bosque mesófilo de montaña (Figura 4). En otros hábitats el número de localidades es considerablemente menor: bosque de pino (47, aunque éste incluye encinos y a otros árboles mesofíticos), selva alta perennifolia (26) y bosque de encino (25). En bosques con una sequía bien marcada la presencia de miembros 
de la subtribu es escasa, como en la selva baja caducifolia donde sólo se conocen 7 localidades. Un porcentaje bajo de localidades presentan áreas de agricultura de temporal y pastizales adyacentes a bosques de encino, mesófilo de montaña y pino. Por otro lado, no se conocen localidades para la subtribu en zonas debajo de los $400 \mathrm{~m}$ de altitud y por encima de los $2600 \mathrm{~m}$ de altitud; la mayoría de ellas en zonas entre 800 y $2000 \mathrm{~m}$ de altitud en las montañas del norte de Oaxaca, la parte externa de la Sierra Madre del Sur y las serranías transistímicas (Figura 5).

Zonas para la conservación de Pleurothallidinae de Oaxaca. Casi todos los sitios de colecta para la subtribu se encuentran dentro de las regiones terrestres prioritarias para la conservación propuestas por Arriaga et al. (2000), tales como las Sierras del Norte de Oaxaca-Mixe, Sierra Sur y Costa de Oaxaca y Selva Zoque-La Sepultura (Figura 6). De las cinco áreas naturales protegidas presentes en Oaxaca sólo la reserva de la biosfera Tehuacán-Cuicatlán cuenta con registros para Pleurothallidinae, pero únicamente con dos localidades. Los distritos que albergan más especies endémicas son Ixtlán (18), Mixe (14), Juchitán (12) y Villa Alta (10). En el caso de las 12 especies en riesgo, 6 han sido registradas en el distrito de Juchitán y 4 en el Mixe; existen otros 6 distritos donde también se reportan estas especies: Ixtlán (3), Choapam (2), Pochutla (2), Tehuantepec (2), Juquila (1) y Miahuatlán (1).

\section{Discusión}

La riqueza de Pleurothallidinae aquí reportada representa el $17.5 \%$ de las orquídeas del estado, sólo la subtribu Laeliinae presenta más taxones en el estado, 216 de acuerdo a Soto y Salazar (2004). Más de la mitad de la riqueza de la subtribu se concentra en dos géneros, Lepanthes y Stelis, con 41 y 31 taxones, respectivamente; otros géneros bien representados en el estado son Acianthera (11 especies), Anathallis y Specklinia (9 especies cada uno). Lepanthes y Stelis son también los géneros con más especies endémicas en Oaxaca; de los 32 endemismos 19 corresponden al primero y 6 al segundo, en tanto que cuatro especies de Acianthera son endémicas. De las especies que se encuentran en riesgo, tres están en la categoría de amenazadas (Anathallis oblanceolata, Barbosella proprepens y Specklinia digitale) y nueve en la categoría de sujeta a protección especial (Acianthera eximia, A. tikalensis, A. violacea, Dryadella guatemalensis, Lepanthes parvula, Specklinia fimbriata, S. endotrachys, S. lateritia y Stelis cobanensis). Acianthera eximia y Anathallis oblanceolata son las únicas especies de la subtribu endémicas a Oaxaca y que se encuentran en alguna categoría de riesgo; la distribución de ambas se restringe a la zona de Pluma Hidalgo. Sin embargo, la segunda de ellas no ha vuelto a ser encontrada en su hábitat desde 1987 y es posible que se haya extinguido. Una situación similar se encontró con Lepanthes nigriscapa la cual no ha vuelto a ser colectada desde 1936, (Soto et al., 2007a).

La Sierra Norte alberga más localidades para Pleurothallidinae en comparación con otras áreas, en cinco municipios en los distritos de Ixtlán (Santiago Comaltepec e Ixtlán de Juárez), Mixe (Totontepec Villa de Morelos) y Villa Alta (Tanetze de Zaragoza y San Juan Juquila Vijanos). La Sierra Norte ha sido bien explorada por botánicos y cuenta con varios estudios (i.e. Ortiz, 1970; Saynes, 1989; Ruiz-Jiménez, 1995; Juárez y Velasco, 2003; Figueroa y Guzmán, 2005; Martínez, 2005). Hasta hace relativamente poco tiempo la zona de los Chimalapas estaba poco explorada debido a su difícil acceso, pero en los últimos años ha sido recolectada y el grupo de las orquídeas ha llegado a ser bien conocido (Ishiki, 1988; Salazar y Hágsater, 1997). La región de la Costa también ha sido bien explorada para la subtribu, pero casi todas las localidades registradas se presentan en zonas montañosas con bosque húmedos de los distritos de Juquila, municipio de Santa Catarina Juquila, y Pochutla, municipio de Pluma Hidalgo. Una situación diferente se presenta en la Sierra Sur, pues a pesar de su gran riqueza florística ha sido poco explorada y casi todos los sitios de colecta para Pleurothallidinae se han registrado en dos municipios de los distritos Miahuatlán (San Jerónimo Coatlán) y Sola de Vega (Villa Sola de Vega). En la Cuenca del Papalopan, Mixteca y Valles Centrales se han registrado muy pocas localidades para la subtribu, en parte porque sus hábitats albergan una baja diversidad para el grupo, sus altas tasas de deforestación y erosión edáfica, así como por el difícil acceso a ellas. Sin embargo, tanto en la Mixteca y en la cuenca del Papaloapan aún existen zonas prácticamente inexploradas, muy poco accesibles y con hábitats que son favorables para las especies de la subtribu; en el distrito Silacayoapan (Mixteca) aún existen manchones de bosque mesófilo de montaña (Hernández y Ruiz, 2005), mientras en la Chinantla baja (Cuenca del Papaloapan) aún se presentan zonas extensas con selva alta perennifolia. Los futuros trabajos florísticos para orquídeas en general y Pleurothallidinae en particular, deberán dirigirse a estas dos regiones, pero también a las zonas que no han sido adecuadamente exploradas en la Sierra Sur.

Dos tercios de las localidades para Pleurothallidinae se registran en el bosque mesófilo de montaña. En Oaxaca este tipo de bosque sólo persiste como manchones en franjas localizadas en las sierras del norte, sur e istmo de Tehuantepec, entre 700 y 2,500 m de altitud. Las condiciones ambientales que caracterizan a este tipo de bosque son las altas precipitaciones $(2,000 \mathrm{~mm}$ anuales o mayores), temperaturas templadas ( 16 a $20{ }^{\circ} \mathrm{C}$ en promedio) y una humedad atmosférica elevada a lo largo del año, debido principalmente a la condensación de la humedad que es acarreada por el viento desde el mar (Rzedowski, 1978; Flores y Manzanero, 1999; Trejo, 2004). Estas son también las condiciones requeridas para el establecimiento y crecimiento de plántulas, 
así como para el desarrollo de las flores de la mayoría de Pleurothallidinae (Christensen, 1992; Hermans, 1993, 1997. 2005; Hermans y Hermans, 1995; Perry, 1998). De modo que en este hábitat es donde la subtribu alcanza su mayor riqueza, más que en cualquier otro ecosistema, llegando a ser uno de los componentes más abundantes de la vegetación epífita que es sumamente diversa (Solano, 1993; Salazar y Soto, 1996). En Oaxaca los elementos arbóreos más representativos de este bosque son Lauraceae, Melastomataceae, Rubiaceae, Quercus, Pinus, Podocarpus, Tersntroemia, Ticodendrum, helechos arborescentes, Engelhardtia mexicana en los bosques de la Sierra Norte y Chiranthodendron pentadactylon en los de la Sierra Sur (Ishiki, 1988; Ruíz-Jiménez, 1995; Campos y Villaseñor, 1995; Salazar y Hágsater, 1997; Flores y Manzanero, 1999; Arellanes, 2000). Muchos de estos árboles son hospederos por las Pleurothallidinae, excepto Pinus que se ha visto que no suele ser un forofito para orquídeas.

Los bosques de pino y de encino por lo general se encuentran rodeando al bosque mesófilo de montaña y son hábitats que también albergan un número importante de localidades para la subtribu. Sin embargo, la mayoría de las especies de Pleurothallidinae se han registrado en sitios donde algunos árboles mesofíticos son un componente importante de la vegetación arbórea, o bien donde el bosque colinda con otros más húmedos. La selva alta perennifolia es un hábitat menos propicio para las plantas de la subtribu, pues en su nivel inferior el dosel impone una sombra excesiva, mientras que los superiores la mayor radiación solar provoca condiciones de sequía (Miranda y Hernández, 1963; Breedlove, 1981; Hágsater et al., 2005). En este tipo de selva las Pleurothallidinae crecen frecuentemente en sitios con suelos inundados, cerca de cuerpos de agua o en colindancia con la sabana, donde la sombra no es excesiva y la disponibilidad de humedad es mayor.

Pleurothallidinae es un grupo básicamente polinizado por dípteros pequeños de las familias Culicidae, Drosophilidae y Sciaridae (Dodson, 1962; van der Pijl y Dodson, 1969; Duque, 1993; Christensen, 1994), grupos que también presentan una mayor riqueza en los bosques nublados. La elevada diversidad de Pleurothallidinae se refleja asimismo en una gran variación floral (Luer, 1986; Pridgeon y Chase, 2001; Pridgeon et al., 2001; Pridgeon, 2005). Caracteres florales tales como coloración, pubescencia en sépalos y labelo, presencia de cristales sobre pétalos, labelos y otras estructuras móviles, emisión de aromas, estructuras que mimetizan sitios para alimentación o crianza atraen polinizadores y, en muchos casos, las relaciones planta-polinizador son muy específicas (Christensen, 1994). Los dípteros tienen capacidad de vuelos en distancias cortas en comparación por ejemplo con otros insectos como las abejas. Por lo que se ha encontrado en varios géneros de estas orquídeas que presentan niveles de flujo genético bajo, lo cual favorece la especiación (Christensen, 1994; Ackerman, 1998; Borba et al.,
2001; Borba y Semir, 2001). Esto explicaría la presencia de muchas especies de distribución restringida ya que nuestros resultados muestran muchos endemismos de Pleurothallidinae, conocidos de una o de muy escasas localidades. La aparición conjunta de varias especies de Lepanthes o Stelis es posible debido a que cada una tiene preferencias específicas por su microhábitat, de manera que sus nichos no se sobreponen y reducen la competencia entre ellas; así no hay una especie dominante en la comunidad sino la coexistencia de un mayor número de ellas (Salazar y Soto, 1996; Hágsater et al., 2005). Fegerstrom (1988) cita tres condiciones que permiten a las especies relacionadas crecer de manera simpátrica: contar con plantas perennes, una selección azarosa de individuos al momento de ocupar los sustratos vacíos y una dispersión aleatoria de las semillas. La primer y tercer condiciones se presentan en Pleurothallidinae, pero no se sabe si las especies tienen las mismas probabilidades para colonizar el sustrato.

En Oaxaca las regiones de Juquila, Pluma HidalgoLoxicha, el cordón del Zempoaltépetl, la Chinantla alta y las sierras transístmicas concentran la mayor riqueza y endemismos para Pleurothallidinae y en ellas el hábitat predominante es el bosque mesófilo de montaña. Estas regiones también albergan la mayor riqueza de orquídeas en el estado, por lo que su protección se debe garantizar en Oaxaca. Desafortunadamente en varias de estas regiones el hábitat está amenazado por prácticas agrícolas inadecuadas, extracción de madera, ramoneo de ganado caprino, apertura de nuevos caminos, aumento de la población humana, así como por los efectos del cambio climático (Soto et al., 2007a). Las escasas áreas naturales protegidas en Oaxaca no presentan hábitats favorables para la subtribu y en ellas su diversidad es muy baja. En cambio, la gran mayoría de localidades se encuentran dentro de las regiones terrestres prioritarias; sin embargo no se han planteado estrategias de su conservación. No obstante, en Oaxaca la mayor parte de la superficie forestal es de propiedad comunal (García, 2000; CONANP, 2005). En el estado existen criterios para la conservación y manejo de bosques propuestos por las propias comunidades, destinando áreas especiales de conservación y aprovechamiento de recursos forestales. Estas comunidades se encargan de proteger, vigilar y manejar el bosque. Varias de estas áreas se presentan en regiones de alta biodiversidad de la Sierra Norte y los Chimalapas, donde coinciden con las zonas de mayor riqueza para Pleurothallidinae. Por lo tanto, la conservación de buena parte de la diversidad de la subtribu depende en buena medida de las iniciativas de conservación de las comunidades de Oaxaca.

\section{Agradecimientos}

El primer autor agradece el apoyo otorgado por la Comisión Nacional para el Conocimiento y Uso de la Biodiversidad (CONABIO CK017) y de la Secretaria de Investigación y 


\section{SOLANO-GÓMEZ ET ȦL.}

Posgrado del IPN (SIP 20060492). La CONANP delegación Oaxaca a través del Ing. Marco Antonio Huerta facilitaron la temática de las áreas naturales protegidas. Finalmente, a quienes hicieron las revisiones de las diferentes versiones del manuscrito que permitieron mejorar su calidad.

\section{Literatura citada}

Ackerman J.D. 1998. Evolutionary potential in orchids: Patterns and strategies for conservation. Selbyana 19:8-14.

Anónimo. 2000. ArcView GIS 3.2. Environmental Systems Research Institute, U.S.A.

Anónimo. 2005. Oaxaca: Distritos, Red de Caminos y Datos Estadísticos de Población y Vivienda. Ángel García García y Asociados, Oaxaca.

Arellanes Y. 2000. Análisis estructural de un bosque mesófilo de montaña de Ticodendrum incognitum en la Sierra Norte de Oaxaca, México. Tesis de licenciatura, Facultad de Ciencias, Universidad Nacional Autónoma de México, México, D.F. 83 pp.

Arriaga L., Espinoza-Rodríguez J.M., Aguilar-Zúñiga C., Martínez-Romero E., Gómez-Mendoza L. y Loa E. (coordinadores). 2000. Regiones Terrestres Prioritarias de México. Comisión Nacional para el Conocimiento y Uso de la Biodiversidad, México, D.F.

Borba E.L. y Semir J. 2001. Pollinator specificity and convergente in fly-pollinated Pleurothallis (Orchidaceae) species: a multiple population approach. Annals of Botany 88:75-88.

Borba E.L., Semir J. y Shepherd G.J. 2001. Self-incompatibility, inbreeding depression and crossing potential in five Brazilian Pleurothallis (Orchidaceae) species. Annals of Botany 88: 89-99.

Breedlove D.E. 1981. Flora of Chiapas Part 1. Introduction to the flora of Chiapas. The California Academy of Sciences. USA.

Campos A. y Villaseñor J.L. 1995. Estudio florístico de la porción central del municipio de San Jerónimo Coatlán, distrito de Miahuatlán (Oaxaca). Boletín de la Sociedad Botánica de México 56:95-120.

Conabio. 1998. Cartografía Digital de México. Fideicomiso Fondo para la Biodiversidad, México, D.F.

CONANP. 2005. Estrategias de Conservación: Certificación de Iniciativas de Conservación Comunitaria. Secretaría de Medio Ambiente y Recursos Naturales, México, D.F.

CONANP. 2007. Áreas Naturales Protegidas (ANP). Secretaria de Medio Ambiente y Recursos Naturales, México, D.F.

Christensen D. 1992. Notes on the reproductive biology of Stelis argentata Lindl. (Orchidaceae: Pleurothallidinae) in eastern Ecuador. Lindleyana 7:28-33.

Christensen D. 1994. Fly pollination in Orchidaceae. En: Arditti, J. Ed. Orchid Biology: Review and Perspectives VI, pp, 415-454. John Wiley \& Sons, New York.

Dodson C.H. 1962. The importance of pollination in the evolution of the orchids of tropical America. American Orchid Society Bulletin 31: 731-735.

Dressler R.L. y Pollard G.E. 1974. El género Encyclia en México. Asociación Mexicana de Orquideología, México, D.F.

Duque O. 1993. Polinización en Pleurothallis. Orquideología 19:55-69.

Fagerstrom T. 1988. Lotteries in communities of sessile organisms. Trends in Ecology and Evolution 3:303-306.
Figueroa S. y Guzmán F.Y. 2005. Listado Florístico en el Municipio Capulalpam de Méndez, Distrito de Ixtlán de Juárez, Oaxaca. Tesis licenciatura, Facultad de Estudios Superiores Iztacala, Universidad Nacional Autónoma de México, Los Reyes Iztacala. $59 \mathrm{pp}$.

Flores A. y Manzanero G. 1999. Los tipos de vegetación del estado de Oaxaca. En: Vásquez-Dávila M.A. Ed. Vegetación y Flora, pp 7-45, Instituto Tecnológico Agropecuario de Oaxaca, Oaxaca.

García F. 2000. Estrategias para la conservación de espacios naturales en el estado de Oaxaca. El Tecolote 9:48-67.

García-Mendoza A.J. 1983. Estudio Ecológico-Florístico de una Región de la Sierra de Tamazulapan, Distrito de Tepescolula, Oaxaca, México. Tesis licenciatura, Facultad de Ciencias, Universidad Nacional Autónoma de México, México, D.F.

García-Mendoza A.J. 2004. Integración del Conocimiento Florístico del Estado. En: García-Mendoza A.J., Ordóñez M.J. y Briones-Salas M. Eds. Biodiversidad de Oaxaca, pp. 305 325, Instituto de Biología, UNAM-Fondo Oaxaqueño para la Conservación de la Naturaleza-World Wildlife Found, México, D.F.

García-Mendoza A. y Torres R. 1999. Estado actual del conocimiento sobre la flora de Oaxaca. En: Vásquez-Dávila M.A. Ed. Flora y Vegetación, pp. 49-86, Instituto Tecnológico Agropecuario de Oaxaca, Oaxaca.

Hágsater E. y Salazar G. (eds.). 1990. Icones Orchidacearum fasc. 1: Orchids of Mexico part 1. Asociación Mexicana de Orquidelogía, México, D.F.

Hágsater E. y Soto M.A. (eds.). 2003. Icones Orchidacearum fasc.5-6: Orchids of Mexico part 2-3. Instituto Chinoín, México, D.F.

Hágsater E., Soto M.A., Salazar G., Jiménez R., López M.A. y Dressler R.L. 2005. Las Orquideas de México. Instituto Chinoín, México.

Halbinger F. y Soto M.A. 1997. Laelias of Mexico. Orquidea (Méx.) 15:1-160.

Hermans J. 1993. Lepanthes: jewels of the cloud forest. Orchid Review 101:304-309.

Hermans J. 1997. Dracula part 4. At home and in captivity. Orchid Review 105:353-357.

Hermans J. 2005. Pleurothallidinae: Cultivation. En: Pridgeon A.M., Cribb P.J., Chase M.W. y Rasmussen F.N. Eds. Genera Orchidacearum Volume 4: Epidendroideae (Part One), pp, 322-324, Oxford University Press, New York, USA.

Hermans J. y Hermans C. 1995. Liliputian adventures. American Orchid Society Bulletin 64:1087-1095.

Hernández B. y Ruiz N. 2005. Implementación de un sistema de información geográfica en el estado de Oaxaca, región Mixteca. Tesis de licenciatura, Instituto Tecnológico Agropecuario de Oaxaca, Oaxaca. 118 pp.

INEGI. 2000. Información Digital: Cartografía de Oaxaca escala 1:250 000. Instituto Nacional de Estadística, Geografía e Informática, México.

Ishiki M. 1988. Las Selvas Bajas Perennifolias del Cerro Salomón, Región de Chimalapa, Relaciones Fitogeográficas. Tesis de maestría, Colegio de Postgraduados, Montecillos, Edo. México. 86 pp.

Juárez G. y Velasco K. 2003. Contribución al Conocimiento de la Flora Vascular del Bosque Mesófilo de Santa Catarina Ixtepeji, Ixtlán, Oaxaca. Memoria de residencia profesional. Instituto 
Tecnológico Agropecuario de Oaxaca, Oaxaca. 134 pp.

Luer C.A. 1986. Icones Pleurothallidinarum I. Systematics of the Pleurothallidinae. Monographs in Systematic Botany from the Missouri Botanical Garden 15:1-81.

Martínez V.M. 2005. Catálogo de las Orquídeas del Bosque Nublado de Ixtlán de Juárez, Oaxaca. Memoria de residencia profesional, Instituto Tecnológico Agropecuario de Oaxaca, Oaxaca. 125 pp.

Miranda F. y Hernández E. 1963. Los tipos de vegetación de México y su clasificación. Boletín de la Sociedad Botánica de México 28:29-178.

Ortiz D. 1970. Contribución al Conocimiento de la Flora de la Sierra de Juárez, Oaxaca. Tesis de licenciatura, Facultad de Ciencias, Universidad Nacional Autónoma de México, México, D.F. 53 pp.

Pérez-García E., Meave J. y Caballero C. 2001. Vegetación y flora de la región de Nizanda, Istmo de Tehuantepec, Oaxaca, México. Acta Botánica Mexicana 56:19-88.

Perry M. 1998. Masdevallia part 1. Basic information. Orchid Review 106:31-35.

Rosado K. y Aguilar M. 2007. Sistema de información geográfica para la subtribu Pleurothallidinae (Orchidaceae) en Oaxaca. Memoria de residencia profesional, Instituto Tecnológico de la Cuenca del Papaloapan, Tuxtepec. 57 pp.

Pridgeon A.M. 2005. Pleurothallidinae: Description. En: Pridgeon A.M., Cribb P.J., Chase M.W. y Rasmussen F.N. Eds. Genera Orchidacearum Volume 4: Epidendroideae (Part One), pp, 319, Oxford University Press, New York, USA.

Pridgeon A.M. y Chase M.W. 2001. A phylogenetic reclassification of Pleurothallidinae (Orchidaceae). Lindleyana 16: 235-271.

Pridgeon A.M., Solano R. y Chase M.W. 2001. Phylogenetic relationships in Pleurothallidinae (Orchidaceae): Combined evidence from nuclear and plastid DNA sequences. American Journal of Botany 88:2286-2308.

Ruiz-Jiménez C.A. 1995. Análisis Estructural del Bosque Mesófilo de la Región de Huautla de Jiménez, (Oaxaca), México. Tesis de licenciatura, Facultad de Ciencias, Universidad Nacional Autónoma de México, México, D.F. 103 pp.

Rzedowski J. 1978. Vegetación de México. Limusa, México, D.F.

Salas S.H. 1990. Un Estudio de la Vegetación en el Municipio de San Juan Mixtepec, Juxtlahuaca, Oaxaca. Tesis de licenciatura, Escuela Nacional de Ciencias Biológicas, Instituto Politécnico Nacional, México, D.F. 38 pp.

Salas S.H., Saynes-Vásquez A. y Schibli L. 2003. Flora de la costa de Oaxaca, México: Lista florística de la región de Zimatán. Boletín de la Sociedad Botánica de México 72:21-58.

Salas S.H., Schibli L., Nava-Zafra A. y Saynes-Vásquez A. 2007. Flora de la costa de Oaxaca, México (2): Lista florística comentada del Parque Nacional Huatulco. Boletín de la Sociedad Botánica de México 81:101-130.
Salazar G. y Soto M.A. 1996. El género Lepanthes Sw. en México. Orquidea (Méx.) 14:1-231.

Salazar G. y Hágsater E. 1997. Diversidad y Conservación de Orquídeas en la Región de Chimalapa, Oaxaca. Reporte final proyecto G-024, México, D.F. 114 pp.

Salazar G., Reyes J., Brachet C. y Pérez J. 2006. Orquídeas y otras Plantas Nativas de la Cañada Cuicatlán, Oaxaca, México. Instituto de Biología, Universidad Nacional Autónoma de México, México, D.F.

Saynes A. 1989. Contribución al Conocimiento Florístico y Fitogeográfico de la Vertiente Sur de la Sierra de San Felipe, Distrito Centro, Oaxaca. Tesis de licenciatura, Escuela Nacional de Estudios Profesionales Zaragoza, Universidad Nacional Autónoma de México, México, D.F. 106 pp.

SEMARNAT. 2002. Norma Oficial Mexicana NOM-059-ECOL2001, Protección ambiental-especies nativas de México de flora y fauna silvestre categoría de riesgo y especificaciones para su inclusión, exclusión, cambio de lista de especies en riesgo. Diario Oficial de la Federación. Marzo 6 de 2002.

Solano R. 1993. El género Stelis Sw. (Orchidaceae: Pleurothallidnae) en México. Orquídea (Méx.) 13:1-112.

Solano R. 2000. Additions to Stelis Sw. (Pleurothallidinae) from Mexico. Lindleyana 15:49-52.

Solano, R., Bello, R. y Vásquez, A. Listado de las orquídeas de la región de Juquila, Oaxaca, México. Naturaleza y Desarrollo 5:5-15.

Soto M.A. 1987. Una revisión de las especies mexicanas de Trichosalpinx suben. Trichosalpinx. Orquídea (Méx.) 10:247-296.

Soto M.A. y Salazar G. 2004. Orquídeas. En: García-Mendoza A.J., Ordóñez M.J. y Briones-Salas M. Eds. Biodiversidad de Oaxaca, pp, 271-295. Instituto de Biología, UNAM-Fondo Oaxaqueño para la Conservación de la Naturaleza-World Wildlife Fund, México, D.F.

Soto M.A., Solano R. y Hágsater E. 2007a. Risk of extinction and patterns of diversity loss in Mexican orchids. Lankesterina 7:114-121.

Soto M.A., Hágsater E., Jiménez R., Salazar G., Solano R., Flores R. y Ruiz I. 2007b. Orchids of Mexico - Digital Catalogue. Instituto Chinoín, México, D.F.

Torres-Colín M.L. 1989. Estudio Florístico y Descripción de la Vegetación del Cerro Guiengola, en el Istmo de Tehuantepec, Oaxaca. Tesis de licenciatura, Escuela Nacional de Estudios Profesionales Iztacala, Universidad Nacional Autónoma de México, Los Reyes Iztacala. 81 pp.

Trejo I. 2004. Clima. En: García-Mendoza A.J., Ordóñez M.J. y Briones-Salas M. Eds. Biodiversidad de Oaxaca, pp, 67-85, Instituto de Biología, UNAM-Fondo Oaxaqueño para la Conservación de la Naturaleza-World Wildlife Found, México, D.F. van der Pijl L. y Dodson C.H. 1969. Orchid Flowers: Their Pollination and Evolution. University of Miami Press, Florida. 
Posgrado del IPN (SIP 20060492). La CONANP delegación Oaxaca a través del Ing. Marco Antonio Huerta facilitaron la temática de las áreas naturales protegidas. Finalmente, a quienes hicieron las revisiones de las diferentes versiones del manuscrito que permitieron mejorar su calidad.

\section{Literatura citada}

Ackerman J.D. 1998. Evolutionary potential in orchids: Patterns and strategies for conservation. Selbyana 19:8-14.

Anónimo. 2000. ArcView GIS 3.2. Environmental Systems Research Institute, U.S.A.

Anónimo. 2005. Oaxaca: Distritos, Red de Caminos y Datos Estadísticos de Población y Vivienda. Ángel García García y Asociados, Oaxaca.

Arellanes Y. 2000. Análisis estructural de un bosque mesófilo de montaña de Ticodendrum incognitum en la Sierra Norte de Oaxaca, México. Tesis de licenciatura, Facultad de Ciencias, Universidad Nacional Autónoma de México, México, D.F. 83 pp.

Arriaga L., Espinoza-Rodríguez J.M., Aguilar-Zúñiga C., Martínez-Romero E., Gómez-Mendoza L. y Loa E. (coordinadores) 2000. Regiones Terrestres Prioritarias de México. Comisión Nacional para el Conocimiento y Uso de la Biodiversidad, México, D.F.

Borba E.L. y Semir J. 2001. Pollinator specificity and convergente in fly-pollinated Pleurothallis (Orchidaceae) species: a multiple population approach. Annals of Botany 88:75-88.

Borba E.L., Semir J. y Shepherd G.J. 2001. Self-incompatibility, inbreeding depression and crossing potential in five Brazilian Pleurothallis (Orchidaceae) species. Annals of Botany 88: 89-99.

Breedlove D.E. 1981. Flora of Chiapas Part 1. Introduction to the flora of Chiapas. The California Academy of Sciences. USA.

Campos A. y Villaseñor J.L. 1995. Estudio florístico de la porción central del municipio de San Jerónimo Coatlán, distrito de Miahuatlán (Oaxaca). Boletín de la Sociedad Botánica de México 56:95-120.

Conabio. 1998. Cartografía Digital de México. Fideicomiso Fondo para la Biodiversidad, México, D.F.

CONANP. 2005. Estrategias de Conservación: Certificación de Iniciativas de Conservación Comunitaria. Secretaría de Medio Ambiente y Recursos Naturales, México, D.F.

CONANP. 2007. Áreas Naturales Protegidas (ANP). Secretaria de Medio Ambiente y Recursos Naturales, México, D.F.

Christensen D. 1992. Notes on the reproductive biology of Stelis argentata Lindl. (Orchidaceae: Pleurothallidinae) in eastern Ecuador. Lindleyana 7:28-33.

Christensen D. 1994. Fly pollination in Orchidaceae. En: Arditti, J. Ed. Orchid Biology: Review and Perspectives VI, pp, 415-454. John Wiley \& Sons, New York.

Dodson C.H. 1962. The importance of pollination in the evolution of the orchids of tropical America. American Orchid Society Bulletin 31: 731-735.

Dressler R.L. y Pollard G.E. 1974. El género Encyclia en México. Asociación Mexicana de Orquideología, México, D.F.

Duque O. 1993. Polinización en Pleurothallis. Orquideología 19:55-69.

Fagerstrom T. 1988. Lotteries in communities of sessile organisms. Trends in Ecology and Evolution 3:303-306.
Figueroa S. y Guzmán F.Y. 2005. Listado Florístico en el Municipio Capulalpam de Méndez, Distrito de Ixtlán de Juárez, Oaxaca. Tesis licenciatura, Facultad de Estudios Superiores Iztacala, Universidad Nacional Autónoma de México, Los Reyes Iztacala. $59 \mathrm{pp}$.

Flores A. y Manzanero G. 1999. Los tipos de vegetación del estado de Oaxaca. En: Vásquez-Dávila M.A. Ed. Vegetación y Flora, pp 7-45, Instituto Tecnológico Agropecuario de Oaxaca, Oaxaca.

García F. 2000. Estrategias para la conservación de espacios naturales en el estado de Oaxaca. El Tecolote 9:48-67.

García-Mendoza A.J. 1983. Estudio Ecológico-Florístico de una Región de la Sierra de Tamazulapan, Distrito de Tepescolula, Oaxaca, México. Tesis licenciatura, Facultad de Ciencias, Universidad Nacional Autónoma de México, México, D.F.

García-Mendoza A.J. 2004. Integración del Conocimiento Florístico del Estado. En: García-Mendoza A.J., Ordóñez M.J. y Briones-Salas M. Eds. Biodiversidad de Oaxaca, pp. 305325, Instituto de Biología, UNAM-Fondo Oaxaqueño para la Conservación de la Naturaleza-World Wildlife Found, México, D.F.

García-Mendoza A. y Torres R. 1999. Estado actual del conocimiento sobre la flora de Oaxaca. En: Vásquez-Dávila M.A. Ed. Flora y Vegetación, pp. 49-86, Instituto Tecnológico Agropecuario de Oaxaca, Oaxaca.

Hágsater E. y Salazar G. (eds.). 1990. Icones Orchidacearum fasc. 1: Orchids of Mexico part 1. Asociación Mexicana de Orquidelogía, México, D.F.

Hágsater E. y Soto M.A. (eds.). 2003. Icones Orchidacearum fasc.5-6: Orchids of Mexico part 2-3. Instituto Chinoín, México, D.F.

Hágsater E., Soto M.A., Salazar G., Jiménez R., López M.A. y Dressler R.L. 2005. Las Orquídeas de México. Instituto Chinoín, México.

Halbinger F. y Soto M.A. 1997. Laelias of Mexico. Orquidea (Méx.) 15:1-160.

Hermans J. 1993. Lepanthes: jewels of the cloud forest. Orchid Review 101:304-309.

Hermans J. 1997. Dracula part 4. At home and in captivity. Orchid Review 105:353-357.

Hermans J. 2005. Pleurothallidinae: Cultivation. En: Pridgeon A.M., Cribb P.J., Chase M.W. y Rasmussen F.N. Eds. Genera Orchidacearum Volume 4: Epidendroideae (Part One), pp, 322-324, Oxford University Press, New York, USA.

Hermans J. y Hermans C. 1995. Liliputian adventures. American Orchid Society Bulletin 64:1087-1095.

Hernández B. y Ruiz N. 2005. Implementación de un sistema de información geográfica en el estado de Oaxaca, región Mixteca. Tesis de licenciatura, Instituto Tecnológico Agropecuario de Oaxaca, Oaxaca. 118 pp.

INEGI. 2000. Información Digital: Cartografía de Oaxaca escala 1:250 000. Instituto Nacional de Estadística, Geografía e Informática, México.

Ishiki M. 1988. Las Selvas Bajas Perennifolias del Cerro Salomón, Región de Chimalapa, Relaciones Fitogeográficas. Tesis de maestría, Colegio de Postgraduados, Montecillos, Edo. México. 86 pp.

Juárez G. y Velasco K. 2003. Contribución al Conocimiento de la Flora Vascular del Bosque Mesófilo de Santa Catarina Ixtepeji, Ixtlán, Oaxaca. Memoria de residencia profesional. Instituto 
Tecnológico Agropecuario de Oaxaca, Oaxaca. 134 pp.

Luer C.A. 1986. Icones Pleurothallidinarum I. Systematics of the Pleurothallidinae. Monographs in Systematic Botany from the Missouri Botanical Garden 15:1-81.

Martínez V.M. 2005. Catálogo de las Orquídeas del Bosque Nublado de Ixtlán de Juárez, Oaxaca. Memoria de residencia profesional, Instituto Tecnológico Agropecuario de Oaxaca, Oaxaca. 125 pp.

Miranda F. y Hernández E. 1963. Los tipos de vegetación de México y su clasificación. Boletín de la Sociedad Botánica de México 28:29-178.

Ortiz D. 1970. Contribución al Conocimiento de la Flora de la Sierra de Juárez, Oaxaca. Tesis de licenciatura, Facultad de Ciencias, Universidad Nacional Autónoma de México, México, D.F. 53 pp.

Pérez-García E., Meave J. y Caballero C. 2001. Vegetación y flora de la región de Nizanda, Istmo de Tehuantepec, Oaxaca, México. Acta Botánica Mexicana 56:19-88.

Perry M. 1998. Masdevallia part 1. Basic information. Orchid Review 106:31-35.

Rosado K. y Aguilar M. 2007. Sistema de información geográfica para la subtribu Pleurothallidinae (Orchidaceae) en Oaxaca. Memoria de residencia profesional, Instituto Tecnológico de la Cuenca del Papaloapan, Tuxtepec. 57 pp.

Pridgeon A.M. 2005. Pleurothallidinae: Description. En: Pridgeon A.M., Cribb P.J., Chase M.W. y Rasmussen F.N. Eds. Genera Orchidacearum Volume 4: Epidendroideae (Part One), pp, 319, Oxford University Press, New York, USA.

Pridgeon A.M. y Chase M.W. 2001. A phylogenetic reclassification of Pleurothallidinae (Orchidaceae). Lindleyana 16: 235-271.

Pridgeon A.M., Solano R. y Chase M.W. 2001. Phylogenetic relationships in Pleurothallidinae (Orchidaceae): Combined evidence from nuclear and plastid DNA sequences. American Journal of Botany 88:2286-2308.

Ruiz-Jiménez C.A. 1995. Análisis Estructural del Bosque Mesófilo de la Región de Huautla de Jiménez, (Oaxaca), México. Tesis de licenciatura, Facultad de Ciencias, Universidad Nacional Autónoma de México, México, D.F. 103 pp.

Rzedowski J. 1978. Vegetación de México. Limusa, México, D.F.

Salas S.H. 1990. Un Estudio de la Vegetación en el Municipio de San Juan Mixtepec, Juxtlahuaca, Oaxaca. Tesis de licenciatura, Escuela Nacional de Ciencias Biológicas, Instituto Politécnico Nacional, México, D.F. 38 pp.

Salas S.H., Saynes-Vásquez A. y Schibli L. 2003. Flora de la costa de Oaxaca, México: Lista florística de la región de Zimatán. Boletín de la Sociedad Botánica de México 72:21-58.

Salas S.H., Schibli L., Nava-Zafra A. y Saynes-Vásquez A. 2007. Flora de la costa de Oaxaca, México (2): Lista florística comentada del Parque Nacional Huatulco. Boletín de la Sociedad Botánica de México 81:101-130.
Salazar G. y Soto M.A. 1996. El género Lepanthes Sw. en México. Orquídea (Méx.) 14:1-231.

Salazar G. y Hágsater E. 1997. Diversidad y Conservación de Orquídeas en la Región de Chimalapa, Oaxaca. Reporte final proyecto G-024, México, D.F. 114 pp.

Salazar G., Reyes J., Brachet C. y Pérez J. 2006. Orquídeas y otras Plantas Nativas de la Cañada Cuicatlán, Oaxaca, México. Instituto de Biología, Universidad Nacional Autónoma de México, México, D.F.

Saynes A. 1989. Contribución al Conocimiento Florístico y Fitogeográfico de la Vertiente Sur de la Sierra de San Felipe, Distrito Centro, Oaxaca. Tesis de licenciatura, Escuela Nacional de Estudios Profesionales Zaragoza, Universidad Nacional Autónoma de México, México, D.F. 106 pp.

SEMARNAT. 2002. Norma Oficial Mexicana NOM-059-ECOL2001, Protección ambiental-especies nativas de México de flora y fauna silvestre categoría de riesgo y especificaciones para su inclusión, exclusión, cambio de lista de especies en riesgo. Diario Oficial de la Federación. Marzo 6 de 2002.

Solano R. 1993. El género Stelis Sw. (Orchidaceae: Pleurothallidnae) en México. Orquídea (Méx.) 13:1-112.

Solano R. 2000. Additions to Stelis Sw. (Pleurothallidinae) from Mexico. Lindleyana 15:49-52.

Solano, R., Bello, R. y Vásquez, A. Listado de las orquídeas de la región de Juquila, Oaxaca, México. Naturaleza y Desarrollo 5:5-15.

Soto M.A. 1987. Una revisión de las especies mexicanas de Trichosalpinx suben. Trichosalpinx. Orquídea (Méx.) 10:247-296.

Soto M.A. y Salazar G. 2004. Orquídeas. En: García-Mendoza A.J., Ordóñez M.J. y Briones-Salas M. Eds. Biodiversidad de Oaxaca, pp, 271-295. Instituto de Biología, UNAM-Fondo Oaxaqueño para la Conservación de la Naturaleza-World Wildlife Fund, México, D.F.

Soto M.A., Solano R. y Hágsater E. 2007a. Risk of extinction and patterns of diversity loss in Mexican orchids. Lankesterina 7:114-121.

Soto M.A., Hágsater E., Jiménez R., Salazar G., Solano R., Flores R. y Ruiz I. 2007b. Orchids of Mexico - Digital Catalogue. Instituto Chinoín, México, D.F.

Torres-Colín M.L. 1989. Estudio Florístico y Descripción de la Vegetación del Cerro Guiengola, en el Istmo de Tehuantepec, Oaxaca. Tesis de licenciatura, Escuela Nacional de Estudios Profesionales Iztacala, Universidad Nacional Autónoma de México, Los Reyes Iztacala. 81 pp.

Trejo I. 2004. Clima. En: García-Mendoza A.J., Ordóñez M.J. y Briones-Salas M. Eds. Biodiversidad de Oaxaca, pp, 67-85, Instituto de Biología, UNAM-Fondo Oaxaqueño para la Conservación de la Naturaleza-World Wildlife Found, México, D.F. van der Pijl L. y Dodson C.H. 1969. Orchid Flowers: Their Pollination and Evolution. University of Miami Press, Florida.

Recibido: 13 de septiembre de 2007

Aceptado: 16 de mayo de 2008 
Apéndice. Lista de las orquídeas de la subtribu Pleurothallidinae cuya presencia en Oaxaca fue confirmada en este trabajo, en cada especie se señalan los distritos y municipios donde han sido registradas. El asterisco $\left(^{*}\right)$ indica que la especie es endémica de Oaxaca. Las letras A (amenazada) y $\operatorname{Pr}$ (sujeta a protección especial) indican la categoría de riesgo para las 12 especies de la subtribu que están incluidas en la lista de la NOM-059-ECOL-2001.

1. Acianthera angustifolia (Lindl.) Solano; Mixe (Totontepec Villa de Morelos).

2. Acianthera chrysantha (Lindl.) Pridgeon et M.W. Chase; Sola de Vega (San Vicente Lachixío), Juquila (Santa Catarina Juquila), Yautepec (Santa María Ecatepec).

3. Acianthera circumplexa (Lindl.) Pridgeon et M.W. Chase; Juchitán (San Miguel Chiamalapa), Pochutla (Candelaria Loxicha), Sola de Vega (Villa Sola de Vega).

4. $\quad{ }^{* A}$ Acianthera eximinia (L.O. Williams) Solano; Pochutla (Pluma Hidalgo, San Miguel del Puerto), Miahuatlán (San Jerónimo Coatlán), Juquila (Santa Catarina Juquila).

5. * Acianthera greenwoodii Soto Arenas; Tlacolula (Santo Domingo Albarradas).

6. Acianthera hartwegiifolia (Kraenzl.) Solano et Soto Arenas, Juquila (Santa Catarina Juquila).

7. Acianthera majakoluckae Soto Arenas et Solano, Juchitán (Santa María Chimalapa).

8. * Acianthera mixe Solano et Soto Arenas, Mixe (Totontepec Villa de Morelos).

9. * Acianthera pollardii Solano et Soto Arenas, Juquila (Santa Catarina Juquila), Tlaxiaco (Santiago Yosondúa).

10. Pr Acianthera tikalensis (D.S. Correll) Solano, Juchitan (Santa María Chimalapa)

11. $\operatorname{Pr}$ Acianthera violacea (A. Rich. et Galeotti) Pridgeon \& M.W. Chase, Mixe (Totontepec Villa de Morelos).

12. Anathallis barbulata (Lindl.) Pridgeon et M.W. Chase, Juchitán (Santa María Chimalapa).

13. * Anathallis greenwoodii Soto Arenas et Salazar, Ixtlán (San Juan Juquila Vijanos).

14. Anathallis involuta (L.O. Williams) Solano et Soto Arenas, Juquila (Santa Catarina Juquila, San Pedro Juchatengo).

15. Anathallis lewisae (Ames) Solano et Soto Arenas, Juchitán (Santa María Chimalapa).

16. Anathallis minutalis (Lindl.) Pridgeon et M.W. Chase, Ixtlán (Ixtlán de Juárez), Miahuatlán (San Jerónimo Coatlán), Juxtlahuaca (Santiago Juxtlahuaca).

17. *A Anathallis oblanceolata (L.O. Williams) Solano et Soto Arenas, Pochutla (Pluma Hidalgo).

18. Anathallis scariosa (La Llave et Lex.) Pridgeon et M.W. Chase, Juquila (San Juan Lachao), Miahuatlán (San Jerónimo Coatlán).

19. Anathallis sertularioides (Sw.) Pridgeon et M.W. Chase, Juchitán (Santa María Chimalapa).

20. Anathallis yucatanenses (Ames et C. Schweinf.) Solano et Soto Arenas, Juchitán (Santa María Chimalapa).

21. A Barbosella prorepens (Rchb. f.) Schltr., Mixe (Totontepec Villa de Morelos).

22. * Dryadella greenwoodiana Soto Arenas, Salazar et Solano, Ixlán (San Juan Juquila Vijanos).

23. PrDryadella guatemalensis (Schltr.) Luer, Choapam (San Juan Lalana).

24. Dryadella linearifolia (Ames) Luer, Choapam (San Juan Lalana), Juchitán (Santa María Chimalapa).

25. Lepanthes acuminata Schltr. subsp. acuminata, Juchitán (San Miguel Chimalapa), Mixe (Totontepec Villa de Morelos), Teotitlán (San José Tenango).

26. Lepanthes appendiculata Ames, Juchitán (Santa María Chimalapa).

27. * Lepanthes aprica Catling et V.R. Catling, Ixtlán (San Juan Juquila Vijanos), Juchitán (San Miguel Chimalapa), Mixe (Totontepec Villa de Morelos), Villa Alta (Tanetze de Zaragoza).

28. * Lepanthes attenuata Salazar, Soto Arenas et O. Suárez, Ixtlán (San Juan Juquila Vijanos), Juchitán (San Miguel Chimalapa), Mixe (Totontepec Villa de Morelos), Teotitlán (San José Tenango), Tuxtepec (San Felipe Usila), Villa Alta (Tanetze de Zaragoza).

29. Lepanthes avis Rchb. f., Tuxtepec (San Felipe Usila), Villa Alta (Tanetze de Zaragoza), Yautepec (San Juan Juquila Mixes).

30. Lepanthes brachystele Salazar et Soto Arenas, Ixtlán (Santa Catarina Ixtepeji), Zimatlán (Zimatlán de Álvarez).

31. Lepanthes breedlovei Salazar et Soto Arenas, Yautepec (San Juan Juquila Mixes).

32. Lepanthes calopetala Salazar et Soto Arenas, Ixtlán (San Juan Juquila Vijanos), Villa Alta (Tanetze de Zaragoza).

33. Lepanthes camposii Salazar et Soto Arenas, Miahuatlán (San Jerónimo Coatlán), Pochutla (Pluma Hidalgo).

34. * Lepanthes catlingii Salazar, Soto Arenas et O. Suárez, Ixtlán (San Juan Juquila Vijanos, Santiago Comaltepec, San Juan Atepec), Mixe (Totontepec Villa de Morelos), Villa Alta (Tanetze de Zaragoza).

35. * Lepanthes chiangii Salazar, Soto Arenas et O. Suárez, Ixtlán (Santiago Comaltepec, San Juan Juquila Vijanos), Villa Alta (Tanetze de Zaragoza).

36. * Lepanthes erythroxantha Salazar et Soto Arenas, Ixtlán (San Juan Juquila Vijanos, Santiago Comaltepec, San Juan Atepec), Tuxtepec (San Felipe Usila), Villa Alta (Tanetze de Zaragoza).

37. * Lepanthes gabriellae Salazar et Soto Arenas, Ixtlán (Santiago Xiacui, San Juan Juquila Vijanos), Tuxtepec (San Felipe Usila), Villa Alta (Tanetze de Zaragoza).

38. * Lepanthes galeottiana Salazar et Soto Arenas, Ixtlán (Capulalpan, Ixtlán de Juárez, San Pablo Macuiltianguis, San Juan Atepec), Mixe (Totontepec Villa de Morelos), Tuxtepec (San Felipe Usila), Villa Alta (San Juan Juquila Vijanos, Tanetze de Zaragoza). 
39. * Lepanthes greenwoodii Salazar et Soto Arenas, Juchitán (San Miguel Chimalapa), Juquila (Santa Catarina Juquila), Miahuatlán (San Jerónimo Coatlán), Yautepec (Santa María Ecatepec), Zimatlán (Zimatlán de Álvarez).

40. Lepanthes guerrerensis Salazar et Soto Arenas, Yautepec (Santa María Ecatepec).

41. * Lepanthes machorroi Salazar et Soto Arenas, Mixe (Totontepec Villa de Morelos), Tuxtepec (San Juan Bautista Valle Nacional).

42. * Lepanthes mariae Salazar et Soto Arenas, Ixtlán (San Juan Juquila Vijanos), Villa Alta (Tanetze de Zaragoza).

43. Lepanthes martinezii Salazar et Soto Arenas, Juchitán (San Miguel Chimalapa).

44. * Lepanthes mazatlanensis Solano et Reynaud, Teotitlán (Mazatlán Villa de Flores).

45. * Lepanthes mixe Salazar et Soto Arenas, Mixe (Totontepec Villa de Morelos).

46. Lepanthes moorei C. Schweinf., Ixtlán (Santiago Xiacui, Santa Catarina Ixtepeji, San Juan Juquila Vijanos, Santiago Comaltepec), Tuxtepec (San Felipe Usila), Villa Alta (Tanetze de Zaragoza), Yautepec (San Juan Juquila Mixes).

47. Lepanthes nagelii Salazar et Soto Arenas, Ixtlán (Santa Catarina Ixtepeji), Zimatlán (Zimatlán de Álvarez).

48. * Lepanthes nigriscapa R.E. Schult. et G.W. Dillon, Pochutla (Pluma Hidalgo).

49. * Lepanthes oaxacana Salazar, Soto Arenas et O. Suárez, Sola de Vega (La Compañía).

50. * Lepanthes oreophila Catling et V.R. Catling, Ixtlán (Santiago Comaltepec), Mixe (Mixistlán de la Reforma, Totontepec Villa de Morelos).

51. Lepanthes papilionacea Salazar, Soto Arenas et O. Suárez, Ixtlán (Santiago Comaltepec).

52. - Pr Lepanthes parvula Dressler, Mixe (Juquila Mixes), Villa Alta (Tanetze de Zaragoza).

53. Lepanthes pollardii Hespenh., Sola de Vega (Villa Sola de Vega), Yautepec (Santa María Ecatepec), Zimatlán (Zimatlán de Álvarez).

54. Lepanthes pristidis Rchb. f., Choapam (San Juan Lalana).

55. Lepanthes rekoi R.E. Schult., Ixtlán (Capulalpan de Méndez, Santiago Comaltepec, San Juan Juquila Vijanos, San Miguel Yotao), Mixe (Totontepec Villa de Morelos), Teotitlán (San Lucas Zoquiapam, Mazatlán Villa de Flores, Tepelmeme de Villa Morelos), Villa Alta (Tanetze de Zaragoza), Yautepec (San Juan Juquila Mixes).

56. Lepanthes samacensis Ames, Juchitán (San Miguel Chimalapa), Yautepec (San Juan Juquila Mixes).

57. * Lepanthes schultesii Salazar et Soto Arenas, Ixtlán (San Juan Juquila Vijanos, San Juan Atepec, San Miguel Yotao), Villa Alta (Tanetze de Zaragoza).

58. Lepanthes scopula Schltr., Juchitán (San Miguel Chimalapa).

59. * Lepanthes sousae Salazar et Soto Arenas, Ixtlán (Santa Catarina Ixtepeji, San Juan Juquila Vijanos).

60. Lepanthes suarezii Salazar et Soto Arenas, Ixtlán (San Juan Juquila Vijanos, Santa Catarina Ixtepeji, Santiago Comaltepec), Tuxtepec (San Felipe Usila), Villa Alta (Tanetze de Zaragoza).

61. Lepanthes tenuiloba R.E. Schult. et G.W. Dillon, Juchitán (San Miguel Chimalapa).

62. Lepanthes thurstoniorum Salazar, Soto Arenas et O. Suárez, Villa Alta (San Juan Juquila Vijanos, Tanetze de Zaragoza).

63. * Lepanthes totontepecensis Salazar et Soto Arenas, Mixe (Totontepec Villa de Morelos).

64. * Lepanthes wendtii Salazar et Soto Arenas, Ixtlán (Capulalpan de Méndez), Juchitán (San Miguel Chimalapa).

65. Lepanthes yuvilensis Catling, Ixtlán (Santa Catarina Ixtepeji), Zimatlán (Zimatlán de Álvarez).

66. Masdevallia floribunda Lindl., Choapam (Santiago Choapam), Teotitlán (Santa María Chilchotla), Tuxtepec (San José Chiltepec)

67. Masdevallia tuerckheimii Ames, Juchitán (San Miguel Chimalapa).

68. Platystele minimiflora (Schltr.) Garay, Choapam (Santiago Choapam, San Juan Lalana).

69. Platystele oxyglossa (Schltr.) Garay, Cuicatlán (San Juan Zautla), Tuxtepec (San Felipe Usila).

70. Platystele pedicellaris (Schltr.) Garay, Juchitán (Santa María Chimalapa).

71. Platystele stenostachya (Rchb. f.) Garay, Juchitán (Matias Romero), Tehuantepec (Guevea de Humboldt).

72. Pleurothallis antonensis L.O. Williams, Ixtlán (Ixtlán de Juárez), Juchitán (San Miguel Chimalapa, Santa María Chimalapa), Villa Alta (Tanetze de Zaragoza).

73. Pleurothallis cardiothallis Rchb. f., Ixtlán (Ixtlán de Juárez, Santiago Comaltepec, San Juan Juquila Vijanos), Juchitán (San Miguel Chimalapa), Teotitlán (San José Tenango), Villa Alta (Tanetze de Zaragoza).

74. Pleurothallis matudana C. Schweinf., Juchitán (San Miguel Chimalapa).

75. Restrepia muscifera (Lindl.) Rchb. f. ex Lindl., Juquila (Santa Catarina Juquila).

76. Restrepiella ophiocephala (Lindl.) Garay et Dunst., Ixtlán (Ixtlán de Juárez), Juchitán (San Miguel Chimalapa), Juquila (Santa Catarina Juquila), Miahuatlán (San Jerónimo Coatlán).

77. Specklinia brighamii (S. Watson) Pridgeon et M.W. Chase, Juchitán (Santa María Chiamlapa).

78. A Specklinia digitale (Luer), Pridgeon et M.W. Chase, Juchitán (Asunción Ixtaltepec, Santa María Chimalapa), Tuxtepec (San Felipe Usila).

79. Pr Specklinia endotrachys (Rchb. f.), Pridgeon et M.W. Chase, Juchitán (San Miguel Chimalapa).

80. Pr Specklinia fimbriata (Ames et C. Schweinf.) Solano, Choapam (San Juan Lalana), Juchitán (Santa María Chimalapa).

81. Specklinia fuegii (Rchb. f.) Solano et Soto Arenas, Juchitán (San Miguel Chimalapa).

82. Pr Specklinia lateritia (Endres ex Rchb. f.) Pridgeon et M.W. Chase, Juchitán (Santa María Chimalapa).

83. Specklinia marginata (Bateman ex Lindl.) Pridgeon et M.W. Chase, Ixtlán (Ixtlán de Juárez), Juchitán (Santa María Chimalapa). 
84. Specklinia pisinna (Luer) Solano et Soto Arenas, Juchitán (Santa María Chimalapa).

85. Specklinia tribuloides (Sw.) Pridgeon et M.W. Chase, Juchitán (Santa María Chimalapa).

86. Stelis chiapasensis Solano, Juchitán (Santa María Chimalapa).

87. Stelis ciliaris Lindl., Pochutla (Pluma Hidalgo).

88. Pr Stelis cobanensis (Schltr.) Pridgeon et M.W. Chase, Choapam (San Juan Petlapa), Ixtlán (Santiago Comaltepec), Juchitán (Santa María Chimalapa, San Miguel Chimalapa), Mixe (Totontepec Villa de Morelos), Tehuantepec (Guevea de Humboldt).

89. Stelis emarginata (Lindl.) Soto Arenas et Solano, Ixtlán (Ixtlán de Juárez), Mixe (San Pedro y San Pablo Ayutla, Totontepec Villa de Morelos), Teotitlán (Huautla de Jiménez, San Miguel Huautepec), Villa Alta (Tanetze de Zaragoza).

90. Stelis endresii Rchb. f., Cuicatlán (San Pedro Teutila), Ixtlán (San Pedro Yolox), Pochutla (Candelaria Loxicha, Pluma Hidalgo).

91. Stelis gracilis Ames, Juchitán (Santa María Chimalapa), Miahuatlán (San Jerónimo Coatlán), Pochutla (Pluma Hidalgo).

92. Stelis greenwoodii Soto Arenas et Solano, Juquila (Santa Catarina Juquila), Juxtlahuac (Santiago Juxtlahuaca), Juchitán (San Miguel Chimalapa), Tlacolula (Santo Domingo Albarradas), Tlaxiaco (Santiago Yosondúa).

93. Stelis guatemalensis Schltr., Juchitán (San María Chimalapa).

94. Stelis hymenantha Schltr., Jamiltepec (Santiago Ixtayutla), Juquila (San Juan Lachao), Pochutla (Pluma Hidalgo).

95. Stelis immersa (Linden ex Rchb. f.) Pridgeon et M.W. Chase, Tuxtepec (San Felipe Usila)

96. Stelis martinezii Solano, Juchitán (San Miguel Chimalapa).

97. Stelis megachlamys (Schltr.) Populin subsp. megachlamys, Ixtlán (Santiago Comaltepec).

98. Stelis microchila Schltr., Juchitán (Santa María Chimalapa).

99. Stelis nicaraguensis (Liebm.) Solano et Soto Arenas, Cuicatlán (San Pedro Jocotipac), Ixtlán (Ixtlán de Juárez), Juchitán (San Miguel Chimalapa, Santa María Chimalapa).

100. * Stelis nonresupinata Solano et Soto Arenas, Yautepec (Santa María Ecatepec).

101. * Stelis oaxacana Solano, Ixtlán (San Juan Juquila Vijanos, Santiago Comaltepec, Santiago Macuiltianguis), Mixe (Santa María Tiltepec, Totontepec Villa de Morelos), Villa Alta (Tanetze de Zaragoza).

102. Stelis ornata (Rchb. f.) Pridgeon et M.W. Chase, Ixtlán (San Juan Juquila Vijanos, Santiago Xiacui, Santiago Comaltepec), Juchitán (San Miguel Chimalapa).

103. Stelis pachyglossa (Lindl.) Pridgeon et M.W. Chase, Cuicatlán (San Pedro Teutila), Ixtlán (Santiago Comaltepec), Juchitán (San Miguel Chimalapa Santa María Chimalapa), Mixe (Totontepec Villa de Morelos), Tehuantepec (Guevea de Humboldt), Teotitlán (San José Tenango), Villa Alta (Tanetze de Zaragoza), Juchitán (San Miguel Chimalapa), Mixe (Totontepec Villa de Morelos), Tuxtepec (San Felipe Usila).

104. Stelis perplexa Ames, Juchitán (Santa María Chimalapa).

105. Stelis platystylis (Schltr.) Solano et Soto Arenas, Cuicatlán (San Pedro Teutila), Ixtlán (Ixtlán de Juárez, Santiago Comaltepec, San Pedro Yolox), Juchitán (San Miguel Chimalapa, Santa María Chiamalapa), Mixe (Totontepec Villa de Morelos), Villa Alta (Tanetze de Zaragoza), Yautepec (San Juan Juquila Mixes).

106. Stelis purpurascens A. Rich. et Galeotti, Cuicatlán (San Pedro Teutila), Ixtlán (Ixtlán de Juárez), Mixe (Totontepec Villa de Morelos), Teotitlán (Eloxochitlán de Flores Magón, Huautla de Jiménez), Villa Alta (Tanetze de Zaragoza).

107. Stelis quadrifida (Llave et Lex.) Solano et Soto Arenas, Miahuatlán (San Mateo Río Hondo), Pochutla (San Miguel del Puerto), Sola de Vega (La Compañía, San Vicente Lachixio).

108. Stelis rubens Schltr., Ixtlán (San Juan Juquila Vijanos, Santiago Comaltepec), Pochutla (Pluma Hidalgo), Tehuantepec (Guevea de Humboldt).

109. Stelis rufobrunnea (Lindl.) L.O. Williams, Ixtlán (Santa Catarina Ixtepeji, Santiago Xiacui), Sola de Vega (San Miguel Sola de Vega), Juquila (Santa Catarina Juquila), Zaachila (San Antonio Chiltepec), Zimatlán (Zimatlán de Álvarez).

110. * Stelis salazarii Solano, Cuicatlán (San Pedro Teutila), Ixtlán (Santiago Comaltepec), Juchitán (San Miguel Chimalapa).

111. * Stelis sotoana Solano, Juquila (San Juan Lachao).

112. Stelis veracrucensis Solano, Ixtlán (San Juan Juquila Vijanos, San Miguel Yotao), Villa Alta (Tanetze de Zaragoza).

113. Stelis vespertina Solano et Soto Arenas, Juchitán (San Miguel Chimalapa).

114. Stelis villosa (Knowles et Westc.) Pridgeon \& M.W. Chase, Juchitán (San Miguel Chimalapa).

115. * Stelis wendti Solano, Ixtlán (Capulalpan de Méndez), Juchitán (San Miguel Chimalapa).

116. * Stelis zapotecana Solano et Soto Arenas ined., Centro (Oaxaca de Juárez), Cuicatlán (San Juan Tepeuxila), Ixtlán (Santa Catarina Ixtepeji), Juquila (San Juan Lachao, San Pedro Mixtepec).

117. Trichosalpinx blaisdellii (S. Watson) Luer, Jamiltepec (Santiago Ixtayutla), Juchitán (Santa María Chimalapa), Juquila (San Juan Lachao), Miahuatlán (San Jerónimo Coatlán).

118. Trichosalpinx ciliaris (Lindl.) Luer, Pochutla (Pluma Hidalgo).

119. Trichosalpinx dura (Lindl.) Luer, Cuicatlán (San Pedro Teutila), Juchitán (Santa María Chimalapa), Pochutla (Pluma Hidalgo).

120. Trichosalpinx nageliana Soto Arenas, Juquila (San Juan Lachao, San Gabriel Mixtepec).

121. Trichosalpinx pringlei (Schltr.) Luer, Centro (Oaxaca de Juárez).

122. Trichosalpinx tamayoana Soto Arenas, Juquila (San Juan Lachao, Santa Catarina Juquila), Pochutla (Pluma Hidalgo). 